\title{
Effect of myocardial Scar detected by Cardiac Magnetic Resonance on perfusion time and short term outcomes after Coronary Artery Bypass Graft Surgery
}

\author{
Kalyan Kancherla ${ }^{1 *}$, Krishna Kancharla², Gaby Weissmann ${ }^{3,4}$, Abdalla A Elagha ${ }^{5,6}$, Swetha Samineni ${ }^{7}$, Peter C Hill ${ }^{8}$, \\ Steven Boyce ${ }^{8,4}$, Anthon Fuisz ${ }^{9}$
}

From 19th Annual SCMR Scientific Sessions

Los Angeles, CA, USA. 27-30 January 2016

\section{Background}

Myocardial viability assessment by late gadolinium enhancement (LGE) on Cardiac Magnetic resonance (CMR) is an important prognostic tool in patients undergoing CABG. We aim to evaluate the association of scar with surgical parameters and 30 day outcomes post CABG as defined by Society of Thoracic Surgeons (STS) database.

\section{Methods}

Patients who underwent LGE CMR between January 2003 and February $2010<1$ month prior to CABG were included. A standard 16 segment model was used for Left ventricular (LV) scar quantification. Patients were categorized into Scar group and No-scar groups. Perfusion time (PT), Cross clamp time (CCT), 30-Day mortality, Ventricular arrhythmia, duration of ventilation, prolonged ICU (ICU-LOS) and hospital stay (H-LOS) were obtained. Chi square test, $\mathrm{t}$ - test, Wilcoxon rank sum tests and multivariate regression analysis was used for data analysis.

\section{Results}

196 patients met the inclusion criteria. 185 CMR studies were available. The median time from CMR study to CABG surgery was $2(1,4)$ days. The mean age of the study population was 63.2 years $( \pm 11.5)$. Seventy-two percent were male. History of prior MI was present in $64 \%$ of patients and prior CABG in 5.4\% patients. Median LV ejection fraction was $38 \%(28,52)$. Cardiopulmonary bypass was used in 118 patients (72\%).

${ }^{1}$ Cardiology, MedStar Health Research Institute, Washington DC, USA Full list of author information is available at the end of the article
There were 133 patients $(72 \%)$ in the scar group and 52 patients (38\%) in the No-scar group. Compared with No-scar group, Scar group has higher proportion of men $78 \%$ Vs $56 \%(\mathrm{p}=0.002)$, History of prior MI $74 \%$ Vs $39 \%$ $(\mathrm{P}=0.0001)$ and lower LVEF $39 \%$ Vs $46(\mathrm{P}=0.038)$.

Perfusion time (70 $\pm 19 \mathrm{~min}$ Vs $60 \pm 15 \mathrm{~min}, \mathrm{P}=0.01)$ and Cross clamp time ( $48 \pm 14 \mathrm{~min}$ Vs $40 \pm 13 \mathrm{~min}, \mathrm{P}=$ $0.004)$ were significantly longer in Scar group. In multivariate model, number of vessels bypassed $(\mathrm{p}<0.0001)$, presence of scar $(\mathrm{p}=0.0075)$, Age $(\mathrm{p}=0.047)$ and lower $\operatorname{LVEF}(\mathrm{p}=0.049)$ were independently associated with longer perfusion time. Number of vessels bypassed $(\mathrm{p}<$ $0.0001)$, presence of scar $(p=0.0009)$ were independently associated with longer cross clamp time. There was no significant difference in 30-Day mortality, arrhythmia, duration of ventilation, prolonged ICU and hospital stay.

\section{Conclusions}

In patients undergoing surgical revascularization, presence of myocardial scar is significantly associated with longer perfusion and cross clamp time independent of traditional predictors. However, there is no significant difference in short term postoperative outcomes based on scar.

\footnotetext{
Authors' details

${ }^{1}$ Cardiology, MedStar Health Research Institute, Washington DC, USA. ${ }^{2}$ Cardiology, Mayo Clinic, Rochester, MN, USA. ${ }^{3}$ Cardiology, MedStar Heart and Vascular Institute, MedStar Washington Hospital Center, Washington DC, USA. ${ }^{4}$ Cardiology, Georgetown University, Washington DC, USA.

${ }^{5}$ Translational Medicine Branch, National Heart, Lung, and Blood Institute, Bethesda, MD, USA. ${ }^{6}$ Cardiology, Cairo University Hospitals, Cairo, Egypt. ${ }^{7}$ Mayo Clinic Health Systems, Austin, MN, USA. ${ }^{8}$ Cardiac Surgery, MedStar Heart and Vascular Institute, MedStar Washington Hospital Center,
} 
Table 1 Short Term Outcomes

\begin{tabular}{ccccc}
\hline Parameters & All patients Mean / Median(IQ)/\% & No-scar Mean / Median(IQ)/\% & Scar group Mean/Median(IQ)/\% & $\mathbf{P}$ value \\
\hline Number of patients & 185 & 52 & 133 \\
Perfusion Time (min) & $67.3( \pm 18.4)$ & $60.4( \pm 14.9)$ & $69.8( \pm 19.0)$ & $48.3( \pm 13.5)$ \\
Cross Clamp Time (min) & $45.98( \pm 13.7)$ & $40.1( \pm 12.5)$ & 4.5 & 0.0129 \\
Short term Mortality (\%) & $4.9(\mathrm{n}=9)$ & 5.8 & 12.0 & 0.0041 \\
Arrhythmias (\%) & 13.0 & $9(5.8,17.0)$ & $9.7(5.9,19.8)$ & 0.71 \\
Total Ventilator Hours & $9.1(5.9,19.3)$ & 30.8 & 29.2 & 0.54 \\
Prolonged ICU-LOS (\%) & 29.67 & 17.6 & 15.6 & 0.84 \\
Prolonged H-LOS (\%) & 16.2 & & 0.74 \\
\hline
\end{tabular}

Washington DC, USA. ${ }^{9}$ Cardiology, Westchester Medical Center, Valhalla, NY, USA.

Published: 27 January 2016

doi:10.1186/1532-429X-18-S1-P85

Cite this article as: Kancherla et al:: Effect of myocardial Scar detected by Cardiac Magnetic Resonance on perfusion time and short term outcomes after Coronary Artery Bypass Graft Surgery. Journal of Cardiovascular Magnetic Resonance 2016 18(Suppl 1):P85.

Submit your next manuscript to BioMed Central and take full advantage of:

- Convenient online submission

- Thorough peer review

- No space constraints or color figure charges

- Immediate publication on acceptance

- Inclusion in PubMed, CAS, Scopus and Google Scholar

- Research which is freely available for redistribution

Submit your manuscript at www.biomedcentral.com/submit
C Biomed Central 